\title{
Visceral obesity determined by CT as a predictor of short-term postoperative complications in ovarian cancer
}

Xianglin Nie

Lin Zhang

Huangyang Meng

Yi Zhong

Yi Jiang

Ting Chen

Wenjun Cheng ( $\nabla$ wenjunchengdoc@163.com )

Jiangsu Province Hospital and Nanjing Medical University First Affiliated Hospital https://orcid.org/0000-0002-3872-4384

\section{Research Article}

Keywords: visceral obesity, CT, ovarian cancer, cytoreductive surgery, short-term complications

Posted Date: December 13th, 2022

DOI: https://doi.org/10.21203/rs.3.rs-1229020/v2

License: (9) This work is licensed under a Creative Commons Attribution 4.0 International License. Read Full License 


\section{Abstract}

Objective: To explore the association between visceral obesity and short-term postoperative complications in patients with advanced ovarian cancer undergoing cytoreductive surgery.

Methods: Medical records were reviewed for patients with advanced epithelial ovarian cancer. Visceral fat area, subcutaneous fat area and total fat area were measured on a single slice at the level of L3/4 of a preoperative CT scan. The Receiver Operating Characteristic (ROC) curve was used to calculate the optimal cut-off value for visceral fat area. Relationships between visceral fat area and characteristics of ovarian cancer patients were analyzed. Univariable and multivariable Logistic regression analyseswere performed to investigate the value of perioperative characteristics of patients on short-term complications.

Results: According to the ROC curve, the best cut-off value of VFA was $93 \mathrm{~cm}^{2}$. Of the 130 patients, $53.8 \%$ (70/130) were presented visceral obesity. Patients with visceral obesity were older than those with nonvisceral obesity ( 58.4 years old vs. 52.1 years old, $p<0.001$ ). The proportion of patients with hypertension was higher $(35.7 \%$ vs. $13.3 \%, p=0.003)$. The total fat area and subcutaneous fat area were higher in patients with visceral obesity $(294.3 \pm 75.5$ vs. $176.2 \pm 68.7, p<0.001 ; 158.9 \pm 54.7$ vs. $121.7 \pm$ $52.6, p<0.001)$. Compared with patients in the non-visceral obese group, patients in the visceral obese group were more likely to have postoperative fever $(21 / 7030.0 \%$ vs. $8 / 601.25 \%, p=0.023)$, leading to a longer length of hospital stay ( 21 days vs. 17 days, $p=0.009$ ). Time from surgery to adjuvant chemotherapy for patients with visceral obesity has been delayed (24 days vs. 19 days, $p=0.037$ ). Multivariate analysis showed that visceral obesity $(\mathrm{OR}=6.451, p<0.001)$ and operation time $(\mathrm{OR}=$ $1.006, p<0.001)$ were independent predictors of postoperative complications.

Conclusion: Visceral obesity is an important risk factor for short-term postoperative complications in patients with advanced ovarian cancer undergoing cytoreductive surgery.

\section{Introduction}

Ovarian cancer is the most lethal gynecologic malignancies [1]. Cytoreductive surgery and chemotherapy are considered the standard treatments for advanced ovarian cancer. Removing all visible tumors during cytoreductive surgery provides the best survival outcome for patients [2]. However, patients with advanced ovarian cancer often have extensive metastases in the abdominal and pelvic cavity, including the omentum, intestine, peritoneum, appendix, liver, abdominal and pelvic lymph nodes [3]. Complete removal of tumors may only be achievable through more aggressive surgery, which may result in higher complication rates, including tissue damage, massive bleeding, prolonged operating time, etc [4]. Therefore, identifying risk factors that can predict short-term complications will provide value for the management of perioperative patients.

Hughes et al. recently reported a significant difference in the overall complication incidence of obese patients and nonobese patients after major abdominal surgery in gastric, rectal and liver cancers [5]. 
Apart from increasing difficulties during cytoreductive surgery, obesity may also contribute to more postoperative complications and higher costs [6]. Body mass index (BMI) is the most common indicator of obesity. However, it cannot be used to describe the distribution of abdominal fat. Recently, visceral fat area (VFA), total fat area (TFA) and subcutaneous fat area (SFA) have been proposed to assess fat distribution in obese patients [7]. Takeuchi et al. found that patients with high visceral fat areas were associated with postoperative complications in gastric cancer [8]. However, whether visceral obesity could predict short-term postoperative complications in patients with ovarian cancer remains unclear. Computed tomography (CT) scans are broadly used to assess the condition of patients with ovarian cancer and are more accurate and sensitive for assessing fat distribution [9-10].

Thus, the aim of this study was to determine the relationship between visceral obesity determined by CT scans and the short-term postoperative complications of ovarian cancer. Visceral obesity is an important predictor of short-term complications after cytoreductive surgery for advanced ovarian cancer.

\section{Methods}

Patients with ovarian cancer undergoing cytoreductive surgery between January 2018 and December 2020 in the First Affiliated Hospital of Nanjing Medical University were included, and a preoperative abdominal CT scan within 3 weeks was included. Those who had incomplete perioperative data or underwent any treatment after CT scan were excluded. All complications occurring within 30 days after surgery were included and classified according to the Clavien-Dindo classification (CDC) [11]. Grade I complications can be treated with antipyretics, diuretics, analgesics, and fluid replacement in the clinic, which were regarded as not clinically significant complications. This study only analyzed complications of grade II and above. If one patient had multiple complications with different grades, the classification of complications was based on the highest complication rate. Extent and complexity of surgery was categorized using a previously described surgical complexity score (SCS) [12], which were defined as low, intermediate, and high (scores 1 to 3,4 to 7 , and $\geq 8$, respectively). This study was approved by the Institutional Review Board at the First Affiliated Hospital of Nanjing Medical University.

Image analysis was performed using ImageJ software (ImageJ; The National Institutes of Health, 105 Washington, MD, USA; version 1.47). Preoperative CT scan images of 130 patients with ovarian cancer at the level of L3-L4 were completely obtained. In this study, VFA, TFA and SFA were measured using a tissue attenuation range of $-190 \sim-30 \mathrm{HU}$ [13]. (Fig. 1)

Statistical analysis: SPSS statistics v24 was used for all statistical analysis. The correlation between VFA and BMI was analyzed by Spearman correlation. The best cut-off value of VFA was determined by the Receiver Operating Characteristic curve (ROC curve). Continuous data are reported as the mean $\pm S D$, and categorical data are reported as numbers (percentage). Comparisons between groups were made by Student's test or Mann-Whitney U test for continuous data and chi-squared test or Fisher's exact test for categorical variable data. A $p$-value $<0.05$ was considered statistically significant. Univariate and multivariate logistic regression analyses were performed to explore the predictors of postoperative 
complications in patients with advanced ovarian cancer undergoing cytoreductive surgery. The variables with a $p$-value $<0.05$ in the univariate analysis were evaluated in a multivariate logistic regression analysis.

\section{Results}

A total of 130 patients were included in this study. We first analyzed the correlation between BMI and VFA, and BMI and VFA were found to have a positive correlation $\left(r^{2}=0.202, p<0.001\right)$ (Fig. 2). Based on shortterm postoperative complications, ROC curve was used to analyze, the curve AUC was 0.702 , and the best cut-off value for VFA was $93 \mathrm{~cm}^{2}$ (sensitivity was $70.8 \%$, specificity was $69.0 \%$ ).

The clinicopathological characteristics of the 130 patients are summarized in Table 1. Their median age was 54 years (range, 24-80 years). There is a lack of visceral obesity standards for the Chinese population based on CT measurements. According to the ROC curve, 93 was determined to be the best cut-off value to divide patients into two groups, visceral obesity and non-visceral obesity. Patients with visceral obesity were older than those with non-visceral obesity (58.4 years old vs. 52.1 years old, $p<$ $0.001)$. TFA and SFA were much higher in the visceral obesity group ( $294.3 \pm 75.5$ vs. $176.2 \pm 68.7, p<$ $0.001 ; 158.9 \pm 54.7$ vs. $121.7 \pm 52.6, p<0.001)$. Patients with visceral obesity were more likely to have hypertension $(35.7 \%$ vs. $13.3 \%, p=0.003)$.

Table 1. Clinicopathological characteristics 


\begin{tabular}{|c|c|c|c|}
\hline \multirow[t]{2}{*}{ Characteristics } & Obesity & Non-obesity & \multirow[t]{2}{*}{$P$-value } \\
\hline & $N=70$ & $N=60$ & \\
\hline Age (years ) & $58.4 \pm 9.4$ & $52.1 \pm 10.6$ & $<0.001$ \\
\hline \multicolumn{4}{|c|}{ Abdominal surgery times $\mathrm{n}(\%)$} \\
\hline$\geq 2$ times & $8(11.4)$ & 10(16.7) & \multirow[t]{2}{*}{0.389} \\
\hline$<2$ times & $62(88.5)$ & $50(83.3)$ & \\
\hline Hypertension n ( \% ) & 25(35.7) & $8(13.3)$ & 0.003 \\
\hline Diabetes n (\% ) & $5(7.1)$ & $1(1.7)$ & 0.287 \\
\hline \multicolumn{4}{|l|}{ Ascites n ( \% ) } \\
\hline$\geq 1000 \mathrm{ml}$ & $20(29.4)$ & $21(35.6)$ & \multirow[t]{2}{*}{0.457} \\
\hline$<1000 \mathrm{ml}$ & $48(70.6)$ & $38(64.4)$ & \\
\hline \multicolumn{4}{|l|}{ ASA n ( \% ) } \\
\hline ASA1 & $33(41.7)$ & $40(66.7)$ & \multirow[t]{3}{*}{0.080} \\
\hline ASA2 & $35(50.0)$ & 19(31.7) & \\
\hline ASA3 & $2(2.9)$ & $1(1.7)$ & \\
\hline \multicolumn{4}{|l|}{ FIGO stage $n(\%)$} \\
\hline III & $57(81.4)$ & $58(96.7)$ & \multirow[t]{2}{*}{0.007} \\
\hline IV & 13(18.6) & $2(3.3)$ & \\
\hline \multicolumn{4}{|l|}{ Histology n (\%) } \\
\hline Serous & $65(92.9)$ & $55(92.9)$ & \multirow[t]{2}{*}{0.800} \\
\hline Non-Serous & $5(7.1)$ & $5(7.1)$ & \\
\hline \multicolumn{4}{|c|}{ Neoadjuvant chemotherapy } \\
\hline Yes & $39(55.7)$ & $28(46.7)$ & \multirow[t]{2}{*}{0.303} \\
\hline No & $31(44.3)$ & $32(53.3)$ & \\
\hline SFA & $158.9 \pm 54.7$ & $121.7 \pm 52.6$ & $<0.001$ \\
\hline TFA & $294.3 \pm 75.5$ & $176.2 \pm 68.7$ & $<0.001$ \\
\hline
\end{tabular}

In patients with visceral obesity, lipoprotein a (LPa) was lower (206.7 \pm 225.5 vs.305.5 $\pm 276.9, P=0.037)$, while triglycerides (TG) (1.8 \pm 0.8 vs. $1.3 \pm 0.6, p=0.012)$ was higher. However, serum CA125 and HE4 levels were not significantly different between the two groups (Table 2). 
Table 2. Preoperative serological test results

\begin{tabular}{|c|c|c|c|}
\hline \multirow[t]{2}{*}{ Characteristics } & Obesity & Non-obesity & \multirow[t]{2}{*}{$P$-value } \\
\hline & $N=70$ & $N=60$ & \\
\hline PT & $10.9 \pm 1.1$ & $11.1 \pm 0.8$ & 0.387 \\
\hline APTT & $26.3 \pm 2.2$ & $26.8 \pm 2.1$ & 0.524 \\
\hline D-dimer & $1.9 \pm 2.1$ & $1.9 \pm 2.1$ & 0.842 \\
\hline ALT & $18.6 \pm 11.7$ & $19.7 \pm 17.3$ & 0.152 \\
\hline AST & $23.6 \pm 9.4$ & $23.9 \pm 11.4$ & 0.286 \\
\hline LDH & $250.8 \pm 146.7$ & $241.5 \pm 153.3$ & 0.811 \\
\hline HDL & $1.1 \pm 0.3$ & $1.1 \pm 0.3$ & 0.926 \\
\hline LDL & $2.9 \pm 0.7$ & $2.9 \pm 0.7$ & 0.402 \\
\hline Lpa & $206.7 \pm 225.5$ & $305.5 \pm 276.9$ & 0.037 \\
\hline TC & $4.6 \pm 0.9$ & $4.6 \pm 0.9$ & 0.221 \\
\hline TG & $1.8 \pm 0.8$ & $1.3 \pm 0.6$ & 0.012 \\
\hline ALB & $38.3 \pm 3.9$ & $38.0 \pm 3.8$ & 0.766 \\
\hline CA125 & $613.8 \pm 951.9$ & $684.8 \pm 1125.6$ & 0.422 \\
\hline HE4 & $316.3 \pm 344.5$ & $291.3 \pm 335.6$ & 0.722 \\
\hline \multicolumn{4}{|c|}{$\begin{array}{l}\text { PT, Prothrombin time. APTT, activated partial thromboplastin time. ALT, alanine aminotransferase. } \\
\text { AST, aspartate aminotransferase. LDH, lactate dehydrogenase. HDL, high-density lipoprotein. LDL, } \\
\text { low-density lipoprotein. Lpa, Lipoprotein(a). TC, Serum total cholesterol. TG, Triglyceride. ALB, Serum } \\
\text { Albumin. Hb, Hemoglobin. TLC, total lymphocyte count. }\end{array}$} \\
\hline
\end{tabular}

Due to the large scope of cytoreductive surgery for advanced ovarian cancer, postoperative complications will increase. We found that $39 \%(51 / 130)$ of patients with advanced ovarian cancer had $\geq 2$ postoperative complications. In addition, we analyzed the correlation between visceral obesity and postoperative complications in patients with stage III-IV disease, and the number of postoperative complications in patients with visceral obesity increased significantly $(p<0.001)$. Patients with visceral obese prolonged the time from surgery to adjuvant chemotherapy $(p=0.037)$. Patients in the visceral obese group were more likely to have postoperative fever $(p=0.023)$ (Table 3$)$. 
Table 3. Intra- and post-operative characteristics 


\begin{tabular}{|c|c|c|c|}
\hline \multirow[t]{2}{*}{ Characteristics } & Obesity & Non-obesity & \multirow[t]{2}{*}{ P-value } \\
\hline & $N=70$ & $N=60$ & \\
\hline Blood loss volume & $971.4 \pm 1101.6$ & $740.0 \pm 588.1$ & 0.053 \\
\hline \multicolumn{4}{|l|}{ Operation time (min) } \\
\hline$<300$ & $43(58.9)$ & $30(41.1)$ & \multirow[t]{2}{*}{0.211} \\
\hline$\geq 300$ & $27(47.4)$ & $30(52.6)$ & \\
\hline \multicolumn{3}{|l|}{ Surgical approach n(\%) } & \multirow[t]{3}{*}{0.387} \\
\hline Open abdomen & $58(82.9)$ & $53(88.3)$ & \\
\hline Laparoscopy to open abdomen & 12(17.1) & $7(11.7)$ & \\
\hline \multicolumn{4}{|l|}{ Scope of operation n(\%) } \\
\hline Bowel resection & 18(25.7) & 13(21.7) & 0.589 \\
\hline Lymph node dissection/biopsy & $32(45.7)$ & $28(46.7)$ & 0.914 \\
\hline Liver resection & $2(2.9)$ & $0(0)$ & $0.545^{\star}$ \\
\hline Diaphragmectomy & $10(14.3)$ & 13(21.7) & 0.272 \\
\hline Ureteral stent implantation & $8(11.4)$ & $6(10.0)$ & 0.793 \\
\hline \multicolumn{4}{|l|}{ SCS } \\
\hline 1 (low) & $8(11.4)$ & $8(13.3)$ & \\
\hline 2(intermediate) & $51(72.9)$ & 42(70.0) & 0.928 \\
\hline 3(high) & 11(15.7) & 10(16.7) & \\
\hline \multicolumn{4}{|l|}{$\mathrm{R} 0 / \mathrm{R} 1$} \\
\hline R0 & $55(78.6)$ & $50(83.3)$ & \multirow[t]{2}{*}{0.492} \\
\hline R1 & 15(21.4) & 10(16.7) & \\
\hline $\mathrm{CDC}$ & $50(71.4)$ & $22(36.7)$ & $<0.001$ \\
\hline CDC1 & 19(27.1) & $2(3.3)$ & 0.079 \\
\hline $\mathrm{CDC} 2$ & $25(35.7)$ & $17(28.3)$ & 0.004 \\
\hline CDC3 & $1(1.4)$ & $1(1.7)$ & 0.383 \\
\hline CDC4 & $5(7.1)$ & $2(3.3)$ & 0.343 \\
\hline Complications & & & \\
\hline
\end{tabular}




\begin{tabular}{|llll|}
\hline & & & \\
\hline Fever & $21(30.0)$ & $8(13.3)$ & 0.023 \\
\hline Incision infection or bleeding & $0(0)$ & $1(1.7)$ & 0.938 \\
\hline Abnormal liver function & $11(15.7)$ & $6(10.0)$ & 0.335 \\
\hline Intestinal obstruction & $2(2.9)$ & $0(0)$ & 0.187 \\
\hline Infection or sepsis & $9(12.9)$ & $7(11.7)$ & 0.837 \\
\hline Thromboembolism & $4(5.7)$ & $2(3.3)$ & 0.519 \\
\hline Blood transfusion rate & $12(17.1)$ & $10(16.7)$ & 0.942 \\
\hline Intestinal fistula & $1(1.4)$ & $0(0)$ & 0.353 \\
\hline Pleural effusion & $9(12.9)$ & $2(3.3)$ & 0.052 \\
\hline Antibiotic using time & $9(5.1)$ & $8(3.1)$ & 0.371 \\
\hline Time to chemotherapy & $24(13.9)$ & $19(7.2)$ & 0.037 \\
\hline ICU admission n(\%) & $5(7.1)$ & $2(3.3)$ & 0.569 \\
\hline Length of hospital stay & $18.2(7.5)$ & $18.6(7.4)$ & 0.758 \\
\hline$*$ Fisher's exact test. CDC, Clavien-Dindo classification. SCS, surgery complexity score. & \\
\hline
\end{tabular}

Postoperative treatment and rehabilitation of patients with fever were reported in Table 4. More types of antibiotics were used in patients with postoperative fever. And the using time of antibiotics and length of hospital stay prolonged significantly $(p<0.001, p<0.001, p=0.009)$ (Table 4$)$.

Table 4

\begin{tabular}{|llll|}
\hline Costoperative treatment and rehabilitation of Patients with high fever \\
\cline { 2 - 4 } & High fever & Non-high fever & P-value \\
\cline { 2 - 3 } & $\mathbf{N}=\mathbf{2 9}$ & $\mathbf{N}=101$ & \\
\hline Length of hospital stay & $21.6(17.5)$ & $17.5(6.3)$ & 0.009 \\
\hline Antibiotic using time & $11(7.3)$ & $7(2.8)$ & $<0.001$ \\
\hline Types of antibiotics & $3(0.8)$ & $2(0.5)$ & $<0.001$ \\
\hline Time to chemotherapy & $24.9(19.9)$ & $21.5(7.4)$ & 0.148 \\
\hline
\end{tabular}

To investigate whether the characteristics of patients with visceral obesity have independent predictive value for the occurrence of complications, univariate and multivariate logistic regression analyses were performed. Univariate analysis showed that visceral obesity, operation time and intraoperative blood loss 
were significantly associated with postoperative complications. In multivariate analysis, visceral obesity $(\mathrm{OR}=6.451, p<0.001)$ and operation time $(\mathrm{OR}=1.006, p=0.009)$ were independent predictors of postoperative complications (Table 5). 
Table 5

Univariate and Multivariate Logistic Regression Analysis

Univariate Logistic
Regression Analysis

$\mathrm{OR}(95 \% \mathrm{Cl})$

$1.013(0.980-1.048)$
$P$. Multivariate Logistic

value Regression Analysis

$\mathrm{OR}(95 \% \mathrm{Cl})$ p. value

0.444

Age (years)

1

0.599

Abdominal surgery times

$\geq 2$ times

$0.761(0.275-2.107)$

$<2$ times

0.751(0.336-1.679)

0.486

Hypertension

0.235(0.027-2.071)

0.192

Diabetes

BMI

$<25$

1

0.556

$\geq 25$

$0.793(0.366-1.717)$

SFA

1.001(0.995-1.007)

0.680

TFA

1.005(1.001-1.009)

0.002

5.778(2.706-12.337)

$<$

0.001

4.770(2.080-10.943)

0.556

vo

0.994(0.971-1.019)

0.649

ALT

1.005(0.971-1.039)

0.787

AST

1.001(0.998-1.003)

0.534

LDH

0.756(0.204-2.793)

0.674

HDL

1.000(0.998-1.001)

0.734

Lpa

1.274(0.745-2.087)

0.401

LDL

1.164(0.721-1.879)

0.534

TG

TC

1.015(0.758-1.611)

0.604

CA125

1.000(1.000-1.001)

0.258

HE4

1.001(1.000-1.002)

0.145

ALB

$<4$

1

0.750 


\begin{tabular}{|c|c|c|c|c|}
\hline & $\begin{array}{l}\text { Univariate Logistic } \\
\text { Regression Analysis }\end{array}$ & $\begin{array}{l}P \\
\text { value }\end{array}$ & $\begin{array}{l}\text { Multivariate Logistic } \\
\text { Regression Analysis }\end{array}$ & $\begin{array}{l}P \\
\text { value }\end{array}$ \\
\hline & $\mathrm{OR}(95 \% \mathrm{Cl})$ & & $\mathrm{OR}(95 \% \mathrm{Cl})$ & \\
\hline$\geq 4$ & $1.124(0.547-2.310)$ & & & \\
\hline ASA & & & & \\
\hline ASA1 & 1 & & & \\
\hline ASA2 & $2.424(0.210-27.933)$ & 0.153 & & \\
\hline ASA3 & $4.353(0.369-51.370)$ & & & \\
\hline Ascites & $0.815(0.384-1.728)$ & 0.593 & & \\
\hline $\begin{array}{l}\text { Neoadjuvant } \\
\text { chemotherapy }\end{array}$ & $1.301(0.650-2.604)$ & 0.457 & & \\
\hline Blood loss volume & $1.001(1.000-1.002)$ & 0.006 & $1.000(1.000-1.001)$ & 0.325 \\
\hline $\begin{array}{l}\text { Operation time } \\
\text { (min) }\end{array}$ & & & & \\
\hline$<300$ & 1 & $<.001$ & $1.005(1.001-1.010)$ & $\begin{array}{l}< \\
0.001\end{array}$ \\
\hline$\geq 300$ & $1.006(1.003-1.009)$ & & & \\
\hline Surgical approach & $1.313(0.460-3.749)$ & 0.663 & & \\
\hline SCS & & & & \\
\hline 1 (low) & 1 & & & \\
\hline 2(intermediate) & $0.234(0.059-0.994)$ & 0.104 & & \\
\hline 3(high) & $0.348(0.118-1.028)$ & & & \\
\hline R0/R1 & $1.184(0.494-2.838)$ & 0.705 & & \\
\hline FIGO stage & & & & \\
\hline III & 1 & 0.703 & & \\
\hline IV & $1.238(0.414-3.706)$ & & & \\
\hline $\begin{array}{l}\text { BMI, Body mass inc } \\
\text { density lipoprotein. } \\
\text { nutritional index. }\end{array}$ & $\begin{array}{l}\text { SFA, subcutaneous fat } \\
\text { a, Lipoprotein(a). TG, } \mathrm{Tr}\end{array}$ & $\begin{array}{l}\text { FA, total } \\
\text { de. ALB, }\end{array}$ & $\begin{array}{l}\text { at area. VO, visceral o } \\
\text { erum Albumin. PNI, pr }\end{array}$ & , high- \\
\hline
\end{tabular}

The AUCs of VFA, SFA, TFA, and BMI were $0.702,0.507,0.609$, and 0.572 , respectively. Compared with SFA, TFA and BMI, VFA can better assess visceral obesity and can better predict short-term complications after ovarian cancer surgery. (Fig. 3) 


\section{Discussion}

Epidemiological evidence confirms that obesity is a risk factor for the onset of a variety of cancers [1415]. To determine obesity, BMI is typically used, and patients with a BMI of $\geq 30 \mathrm{~kg} / \mathrm{m}^{2}$ are defined as obese. However, BMI does not reflect the whole-body fat distribution [16]. Traditionally, intra-abdominal fat is indirectly measured by waist circumference, hip circumference or waist-to-hip ratio [17]. Whereas, these parameters do not reflect the distribution of body fat either. In the present study, CT was used to measure the visceral fat area directly. Our results showed that patients could have visceral obesity even with a normal BMI. Nevertheless, an appropriate range of CT values for adipose tissue segmentation has not yet been determined. In a recent study, visceral obesity in females was defined as $>80.1 \mathrm{~cm}^{2}$, using metabolic syndrome (MetSyn) as an indicator of obesity-associated dysmetabolism in obesityassociated cancer [18-19]. Heus et al. found that the visceral fat area threshold was $100 \mathrm{~cm}^{2}$ and 130 $\mathrm{cm}^{2}$, and $100 \mathrm{~cm}^{2}$ had a better correlation with postoperative complications [20]. In the present study, ROC curve was used to define the best cutoff value. The incidence of complications after cytoreductive surgery increased significantly in patients with visceral obesity. This suggests that providers should design strategies to reduce complications and be more aware of the possibility of complications.

The occurrence of postoperative complications is an important unfavorable factor for the rapid recovery of patients [21]. It is particularly critical to identify the factors predicting postoperative complications. Severe complications can be the result of complex procedures. These complications can result in delays of the start of adjuvant therapy, which can worsen the condition. In a study of 369 patients who had an abdominal or laparoscopic procedure for proven or suspected gynecological cancer, KondalsamyChennakesavan et al. demonstrated that surgical complexity was one of the independently predictive factors of an adverse events [22]. In our study, the complexity of the operation was scored by SCS. Univariate analysis also showed that SCS weas significantly associated with postoperative complications, while result of multivariate analysis was not. The reason for this inconsistency may be due to small size of enrolled patients.

Whether visceral obesity can be used to predict postoperative complications in patients has been controversial. C. Heus et al. found that patients with visceral obesity had an increased risk of postoperative complications [23]. In contrast, the study by Rutten et al. showed that there was no correlation between visceral obesity and postoperative complications [24]. It is worth noting that the characteristics of the patients included in these two studies were not consistent. Moreover, the operation period was also inconsistent, and the selected CT scan images and method of measurement were also different. In this study, VFA was manually traced on a single transverse slice at the level of L3-L4. Importantly, visceral obesity defined as a VFA of $\geq 93 \mathrm{~cm}^{2}$ was identified as an independent prognostic factor associated with postoperative complications. In addition, Boutin et al. found that there was no significant relationship between adipose tissue distribution and postoperative complications in patients with soft tissue sarcoma [25]. The results from three studies on complications of radical resection of gastrointestinal tumors revealed that an increase in visceral fat could lead to a prolonged operation time, 
poor recovery and postoperative complications [26-28]. These studies suggest that visceral obesity may only have predictive value in certain types of tumors.

Postoperative fever is common in patients undergoing cytoreductive surgery. A postoperative body temperature rise $\left(<38.3^{\circ} \mathrm{C}\right)$ does not require special treatment [29]. In this study, we found that patients with visceral obesity were more likely to have postoperative fever and a postoperative body temperature $\geq 38.3^{\circ} \mathrm{C}$. Adipose tissue is the primary site for storing and mobilizing lipids: it is also associated with endocrine and metabolic functions and contains multiple immune cells [30]. Weisberg et al. demonstrated that the number of macrophages increases during obesity, and the expression of TNF-a and IL- 6 are induced, which activate the inflammatory pathway [31]. Similarly, the low levels of adiponectin in obese patients may increase postoperative insulin resistance and induce inflammation [32]. Therefore, the increase in postoperative fever in patients with visceral obesity may be related to the greater release of these inflammatory factors, but this needs further study.

In this study, preoperative CT images were used to assess the incidence of postoperative complications. Visceral obesity was defined as $>93 \mathrm{~cm}^{2}$, which improved the applicability in clinical practice. Our study confirmed that BMI is a weak indicator for short-term surgical and recovery outcomes after cytoreductive surgery. However, this study also has some limitations. First, it was a single-center and retrospective study that produced inherent and unavoidable biases. Second, In China, due to the lack of rehabilitation institutions to assist in the management of postoperative patients, most patients need to recover in the hospital after surgery, which leading to a relatively long hospital stay. At the same time, the length of hospital stay is prolonged also because of the immediate postoperative chemotherapy. Meanwhile, it may help us observe mild complications. Last, the sample size was small. The number of samples needs to be increased to further prove that visceral obesity is an independent predictor of short-term complications of cytoreductive surgery for ovarian cancer.

\section{Declarations}

\section{Author contributions}

Xianglin Nie, Lin Zhang, Wenjun Cheng made substantial contributions to the project administration, visualization, writing of original draft, review and editing of the manuscript. Xianglin Nie, Huangyang Meng and Yi Zhong made substantial contributions to patient selection and clinical data. Yi Jiang made substantial contributions to review the records. Ting chen made substantial contributions to the usage of CT and ImageJ. All authors approved this final version of the manuscript.

\section{Declaration of Competing Interest}

The authors declare no relevant conflicts of interest.

\section{Funding}


This study was supported by the National Natural Science Foundation(No. 81872119, 82103286), Traditional Chinese Medicine Science and Technology Development Project in Jiangsu Province(ZD202014),Jiangsu Province Policy Guidance Program (International Science and Technology Cooperation/Hong Kong, Macao and Taiwan Science and Technology Cooperation) (BZ2020009), 333 High-level Talents Training Project in Jiangsu Province (BRA2019097).Innovative Team of Jiangsu Province(CXTDA2017008), Youth Scientist Fund of Jiangsu Basic Research Program (BK20210971), Natural Science Research Program of Higher Education Institutions in Jiangsu Province (20KJB320016), Scientific Research Project of Jiangsu Province Maternal and Child Health Association (No. FYX201909)

We thank the medical record room staff for their assistance in retrieving the patients' medical records.

\section{Patient consent for publication Not required.}

Provenance and peer review Not commissioned; externally peer reviewed.

\section{References}

1. Siegel RL, Miller KD, Jemal A (2020) Cancer statistics, 2020. CA Cancer J Clin 70(1):7-30

2. Ignace Vergote MD, Ph D, Claes G, Tropé MD, Ph D, Frédéric Amant MD (2010) Ph.D: Neoadjuvant Chemotherapy or Primary Surgery in Stage IIIC or IV Ovarian Cancer. N Engl J Med 363(10):943-953

3. Aletti GD, Cliby WA (2006) Importance of surgical aggressiveness in advanced ovarian cancer. J Clin Oncol 24(15):2397

4. Harter P, Sehouli J, Lorusso D, Reuss A, Vergote I, Marth C, Kim JW, Raspagliesi F, Lampe B, Aletti G et al (2019) A Randomized Trial of Lymphadenectomy in Patients with Advanced Ovarian Neoplasms. N Engl J Med 380(9):822-832

5. Hughes TM, Shah K, Noria S, Pawlik T (2018) Is BMI associated with post-operative complication risk among patients undergoing major abdominal surgery for cancer? A systematic review. J Surg Oncol 117(5):1009-1019

6. Sung H, Siegel RL, Torre LA, Pearson-Stuttard J, Islami F, Fedewa SA, Goding Sauer A, Shuval K, Gapstur SM, Jacobs EJ et al (2019) Global patterns in excess body weight and the associated cancer burden. CA Cancer J Clin 69(2):88-112

7. Zeng Q, Wang L, Dong S, Zha X, Ran L, Li Y, Chen S, Gao J, Li S, Lu Y et al (2021) CT-derived abdominal adiposity: Distributions and better predictive ability than BMI in a nationwide study of 59,429 adults in China. Metabolism 115:154456

8. Takeuchi M, Ishii K, Seki H, Yasui N, Sakata M, Shimada A, Matsumoto H (2016) Excessive visceral fat area as a risk factor for early postoperative complications of total gastrectomy for gastric cancer: a retrospective cohort study. BMC Surg 16(1):54

9. Irlbeck T, Massaro JM, Bamberg F, O'Donnell CJ, Hoffmann U, Fox CS (2010) Association between single-slice measurements of visceral and abdominal subcutaneous adipose tissue with volumetric measurements: the Framingham Heart Study. Int J Obes (Lond) 34(4):781-787 
10. Yoon DY, Moon JH, Kim HK et al (2008) Comparison of low-dose CT and MR for measurement of intra-abdominal adipose tissue: a phantom and human study. Acad Radiol 15(1):62-70

11. Dindo D, Demartines N, Clavien PA (2004) Classification of surgical complications: a new proposal with evaluation in a cohort of 6336 patients and results of a survey. Ann Surg 240(2):205-213

12. Giovanni D, Aletti A, Santillan EL, Eisenhauer et al (2007) A new frontier for quality of care in gynecologic oncology surgery: Multi-institutional assessment of short-term outcomes for ovarian cancer using a risk-adjusted model. Gynecol Oncol 107(1):99-106

13. Noumura Y, Kamishima T, Sutherland K et al (2017) Visceral adipose tissue area measurement at a single level: Can it represent visceral adipose tissue volume? Br J Radiol 90(1077):20170253

14. Bianchini F, Kaaks R, Vainio H (2002) Overweight, obesity, and cancer risk. Lancet Oncol 3(9):565574

15. lyengar NM, Gucalp A, Dannenberg AJ, Hudis CA (2016) Obesity and Cancer Mechanisms: Tumor Microenvironment and Inflammation. J Clin Oncol 34(35):4270-4276

16. Baczewska M, Bojczuk K, Kolakowski A, Dobroch J, Guzik P, Knapp P (2021) Obesity and Energy Substrate Transporters in Ovarian Cancer-Review. Molecules 26(6):1659

17. Hidetoshi Kashihara JS, Lee K, Kawakubo M, Tamura AA (2009) Criteria of Waist Circumference According to Computed Tomography-Measured Visceral Fat Area and the Clustering of Cardiovascular Risk Factors. Circ J 73(10):1881-1886

18. Doyle SL, Donohoe CL, Lysaght J, Reynolds JV (2012) Visceral obesity, metabolic syndrome, insulin resistance and cancer. Proc Nutr Soc 71(1):181-189

19. Doyle SL, Bennett AM, Donohoe CL, Mongan AM, Howard JM, Lithander FE, Pidgeon GP, Reynolds JV, Lysaght $J$ (2013) Establishing computed tomography-defined visceral fat area thresholds for use in obesity-related cancer research. Nutr Res 33(3):171-179

20. Heus C, Cakir H, Lak A, Doodeman HJ, Houdijk AP (2016) Visceral obesity, muscle mass and outcome in rectal cancer surgery after neo-adjuvant chemo-radiation. Int J Surg 29:159-164

21. Grimm C, Harter P, Alesina PF, Prader S, Schneider S, Ataseven B, Meier B, Brunkhorst V, Hinrichs J, Kurzeder $C$ et al (2017) The impact of type and number of bowel resections on anastomotic leakage risk in advanced ovarian cancer surgery. Gynecol Oncol 146(3):498-503

22. Kondalsamy-Chennakesavan S, Bouman C, DeJong et al (2009) Clinical audit in gynecological cancer surgery: Development of a risk scoring system to predict adverse events. Obstet Gynecol Surv 115(3):329-333

23. Heus $C$, Smorenburg A, Stoker $J$ et al (2021) Visceral obesity and muscle mass determined by CT scan and surgical outcome in patients with advanced ovarian cancer. A retrospective cohort study. Gynecol Oncol 160(1):187-192

24. Rutten IJ, Ubachs J, Kruitwagen RF, van Dijk DP, Beets-Tan RG, Massuger LF, Olde Damink SW, Van Gorp T (2017) The influence of sarcopenia on survival and surgical complications in ovarian cancer patients undergoing primary debulking surgery. Eur J Surg Oncol 43(4):717-724 
25. Boutin RD, Katz JR, Chaudhari AJ, Yabes JG, Hirschbein JS, Nakache YP, Seibert JA, Lamba R, Fananapazir G, Canter RJ et al (2020) Association of adipose tissue and skeletal muscle metrics with overall survival and postoperative complications in soft tissue sarcoma patients: an opportunistic study using computed tomography. Quant Imaging Med Surg 10(8):1580-1589

26. Taniguchi Y, Kurokawa Y, Takahashi T, Saito T, Yamashita K, Tanaka K, Makino T, Yamasaki M, Nakajima K, Eguchi H et al (2021) Impacts of Preoperative Psoas Muscle Mass and Visceral Fat Area on Postoperative Short- and Long-Term Outcomes in Patients with Gastric Cancer. World J Surg 45(3):815-821

27. Tong DQ, Yang CH, Zhao Z, Bo ZH, Xi DW et al (2021) Influence of body composition, muscle strength, and physical performance on the postoperative complications and survival after radical gastrectomy for gastric cancer: A comprehensive analysis from a large-scale prospective study. Clin Nutr 40(5):3360-3369

28. Yang SJ, Li HR, Zhang WH, Liu K, Zhang DY, Sun LF, Chen XL, Zhao LY, Chen XZ, Yang K et al (2020) Visceral Fat Area (VFA) Superior to BMI for Predicting Postoperative Complications After Radical Gastrectomy: a Prospective Cohort Study. J Gastrointest Surg 24(6):1298-1306

29. Yu Y, Pu J, Wu T, Hu L (2021) The characteristics and influencing factors of fever in postoperative patients undergoing percutaneous nephrolithotomy: A retrospective analysis. Med (Baltim) 100(32):e26485

30. Saltiel AR, Olefsky JM (2017) Inflammatory mechanisms linking obesity and metabolic disease. J Clin Invest 127(1):1-4

31. Weisberg SP, McCann D, Desai M, Rosenbaum M, Leibel RL, Ferrante AW (2003) Obesity is associated with macrophage accumulation in adipose tissue. J Clin Invest 112(12):1796-1808

32. Arita Yukio K, Shinji O, Noriyuki T, Masahiko M, Kazuhisa et al (1999) Paradoxical decrease of an adipose-specific protein, adiponectin, in obesity. Biochem Biophys Res Commun 257(1):79-83

\section{Figures}




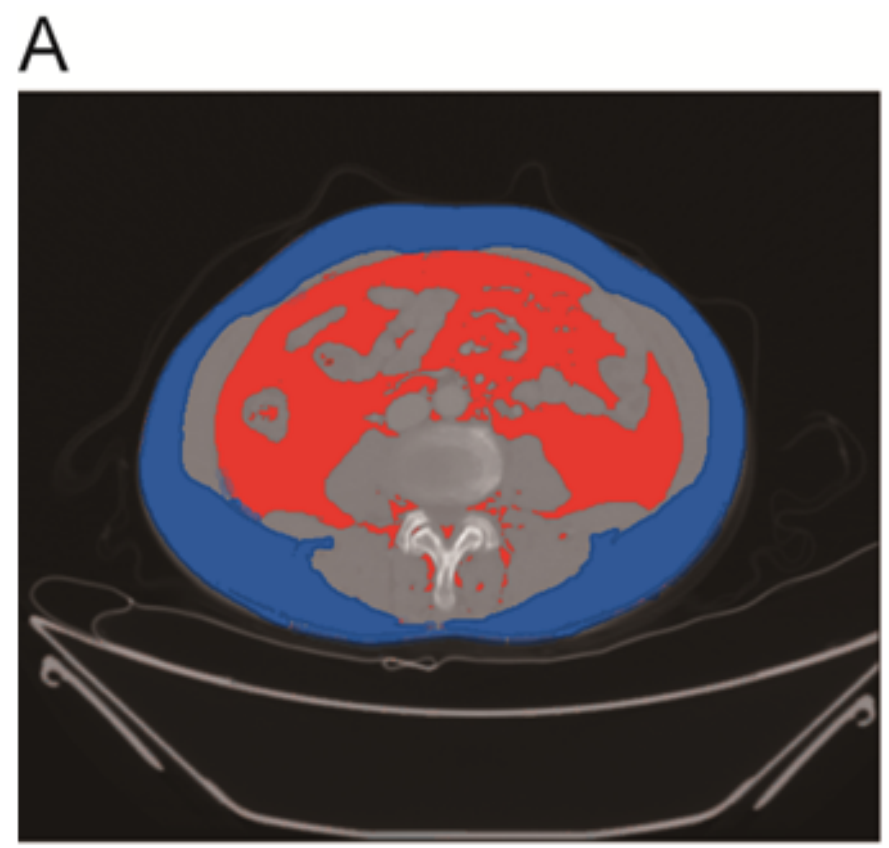

\section{B}

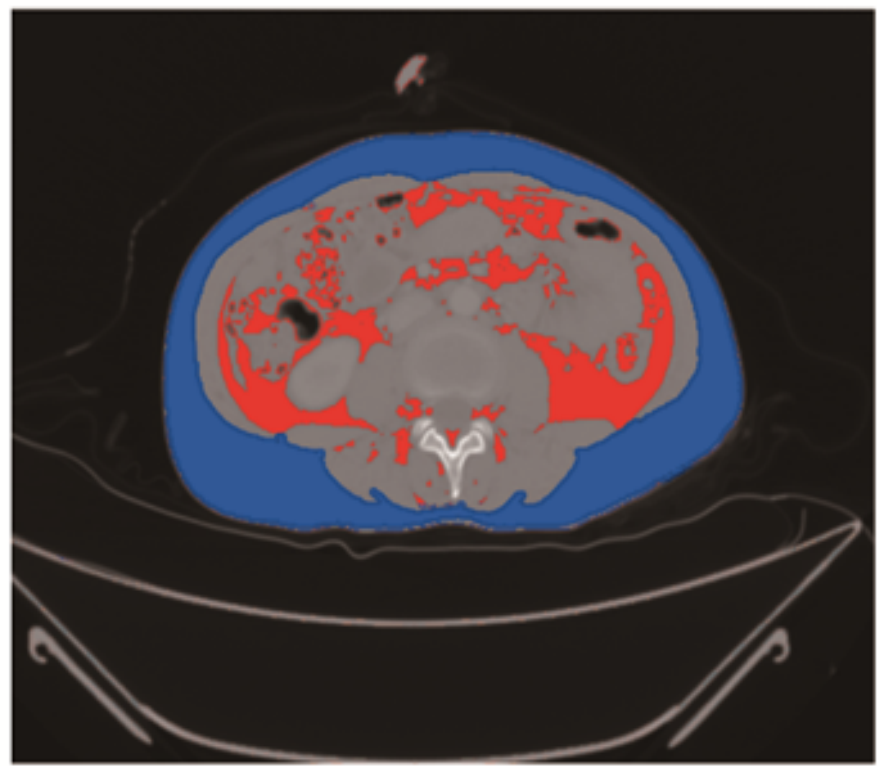

\section{Figure 1}

Visceral fat area, subcutaneous fat area and total fat area were measured on a single slice atthe level of L3/4 of a preoperative CT scan. a. Visceral obesity. b. Nonvisceral obesity

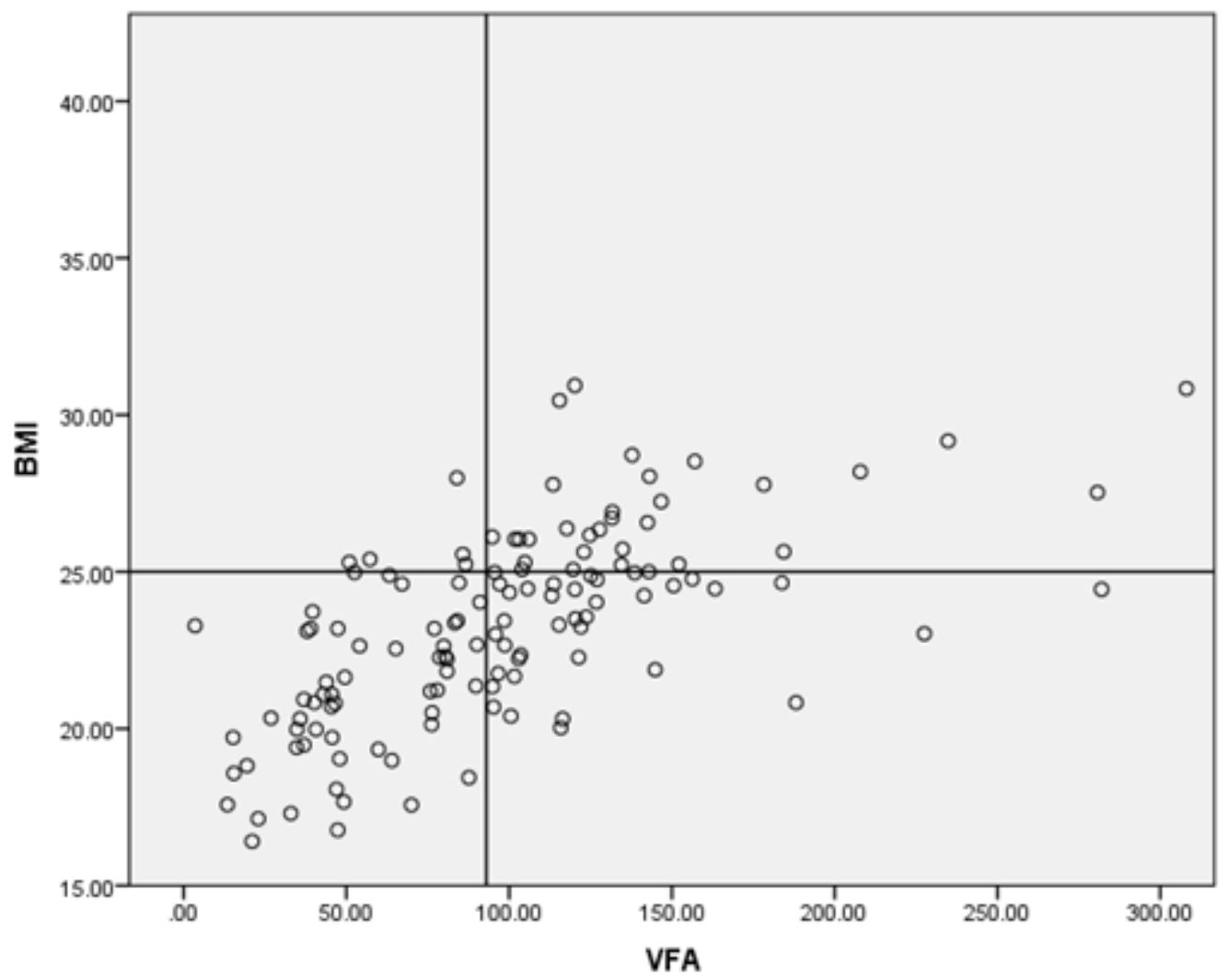


Figure 2

Correlation between BMI and VFA. BMI, Body mass index. Visceral fat area.

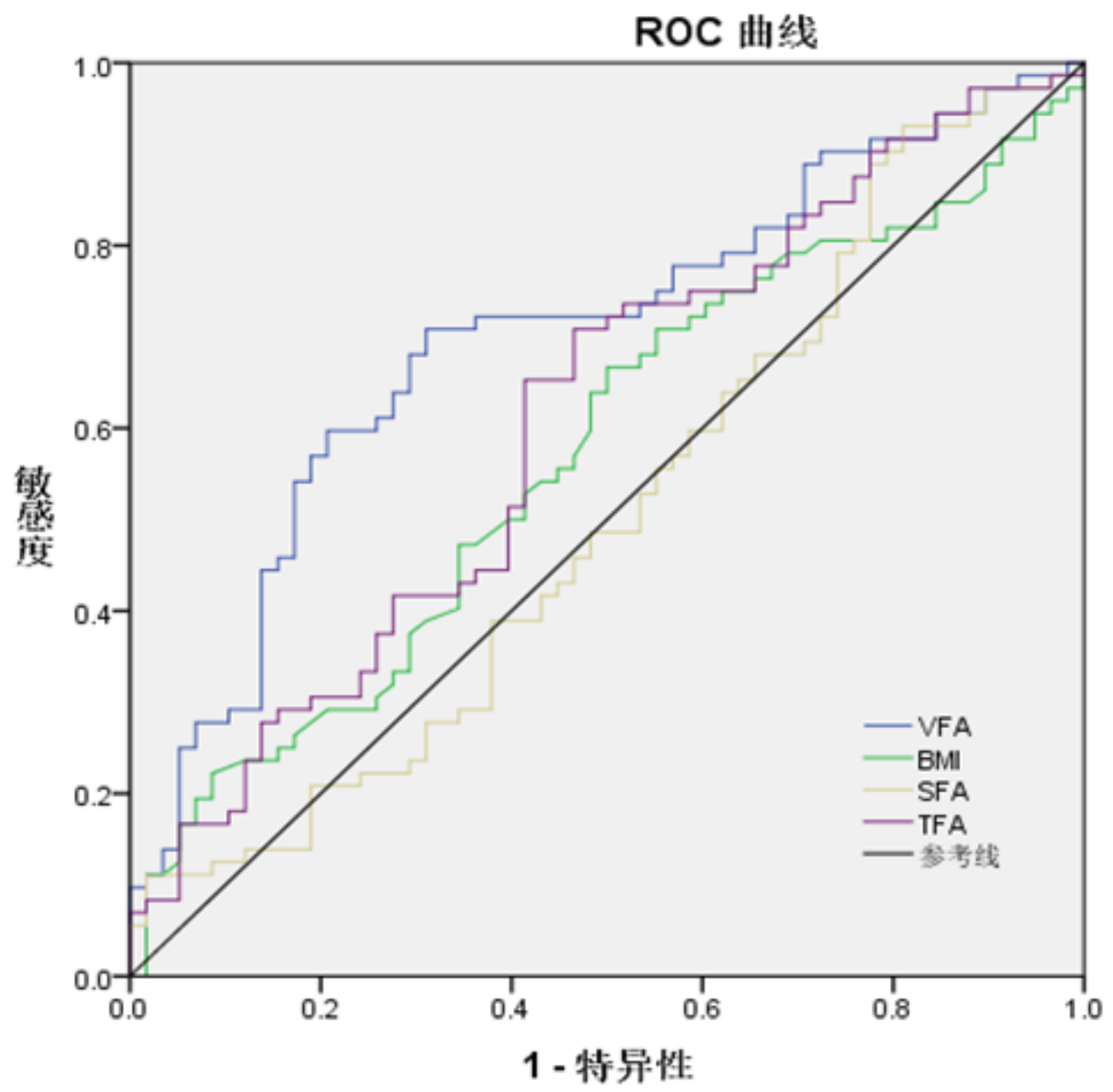

Figure 3

The AUCs of VFA, SFA, TFA, and BMI 